\title{
Effects of grain size on landscape patterns in mineral resource zones: a case study of Wu'an, China
}

\author{
Jianjun Zhang $\cdot$ Yongheng Rao $\cdot$ Yang Xu $\cdot$ Meichen Fu
}

Received: 6 June 2014/Revised: 7 July 2014/ Accepted: 20 July 2014/Published online: 10 October 2014

(C) The Author(s) 2014. This article is published with open access at Springerlink.com

\begin{abstract}
A mineral resource zone, rich in resources and energy, is intensively developed and disturbed by human activities, which causes an obvious change of landscapes. Taking Wu' an of Hebei Province, China, as a case study, this paper extracts landscape information of mineral resource zones through overlapping mineral resources distribution map and landscape pattern map. And then, various landscape indices are selected for analyzing the effects of grain size (30,60, $90,120,150,180,210,240,270$ and $300 \mathrm{~m}$ ) on landscape patterns. Due to different kinds of landscape information transmitted by indices, the changing trends vary with the increase of grain sizes. Accordingly the landscape indices are classified into three types of effects: disturbance, continuity and sustainability, and each type of effect has its own optimal range for grain sizes. Then the optimal range of grain size on landscape patterns in mineral resource zones is gained through a comparison of the effects in various grain sizes of landscape indices. The best first domain of scale covers 30-90 m, with a suitable grain size of 30-60 m before intensive mining and a suitable grain size of 60-90 m after intensive mining. Besides, the suitable grain sizes for reflecting disturbance, continuity and sustainability before intensive mining are 30-60, 30-60 and 30-90 m, respectively, however, the sizes are changed to 60-90, 60-90 and 30-90 m, respectively, after intensive mining. The results are helpful for rational land use and optimal landscape allocation.
\end{abstract}

Keywords Landscape pattern $\cdot$ Grain size $\cdot$ Mineral resource zone $\cdot$ Disturbance

\section{Introduction}

Population, resources and environments have significantly impacted the development of human society. With the advancement of industrialization, the exploration of mineral resources plays an important role in production of food and materials. By the statistics, over $95 \%$ of energy, over $80 \%$ of industrial raw materials and over $70 \%$ of agricultural production materials come from mineral resources (Yan et al. 1992), supporting the operation of $70 \%$ of national GDP ( $\mathrm{Li}$ 2004). However, over exploration of mineral resources exceeds the ability of self-renewal and recovery of nature, causing formation of gobs, surface subsidence, surface cracks,

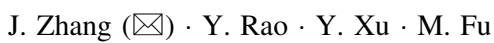

School of Land Science and Technology, China University of Geosciences, Beijing, China

e-mail: zhangjianjun_bj@126.com land pollutions and land occupation, etc. (Zhang et al. 2007). One of obvious external indications is characterized by changes of land use patterns. The changes also cause one of the most profound human-induced alterations of the earth's system (Vitousek et al. 1997), mainly including shaping of native and semi-natural vegetation (McIntyre and Lavorel 2007).

As a measurement of spatial allocation and structure of land use patterns, landscape indices has become a useful tool in the study of land uses and landscapes. Generally speaking, the calculation of landscape indices takes raster data as sources, and the size of grid cells may impact calculated results. Especially in the areas composed of a great number of small and smart patches, which may be "swallowed up" by dominant landscapes. For this scientific problem, some scholars did some research and concluded that landscape indices change accordingly with different grain sizes (grid cells) (Turner et al. 1989; Qi and Wu 1996). Inspired from theories and methods above, mining activities may be more sensitive to changes of 


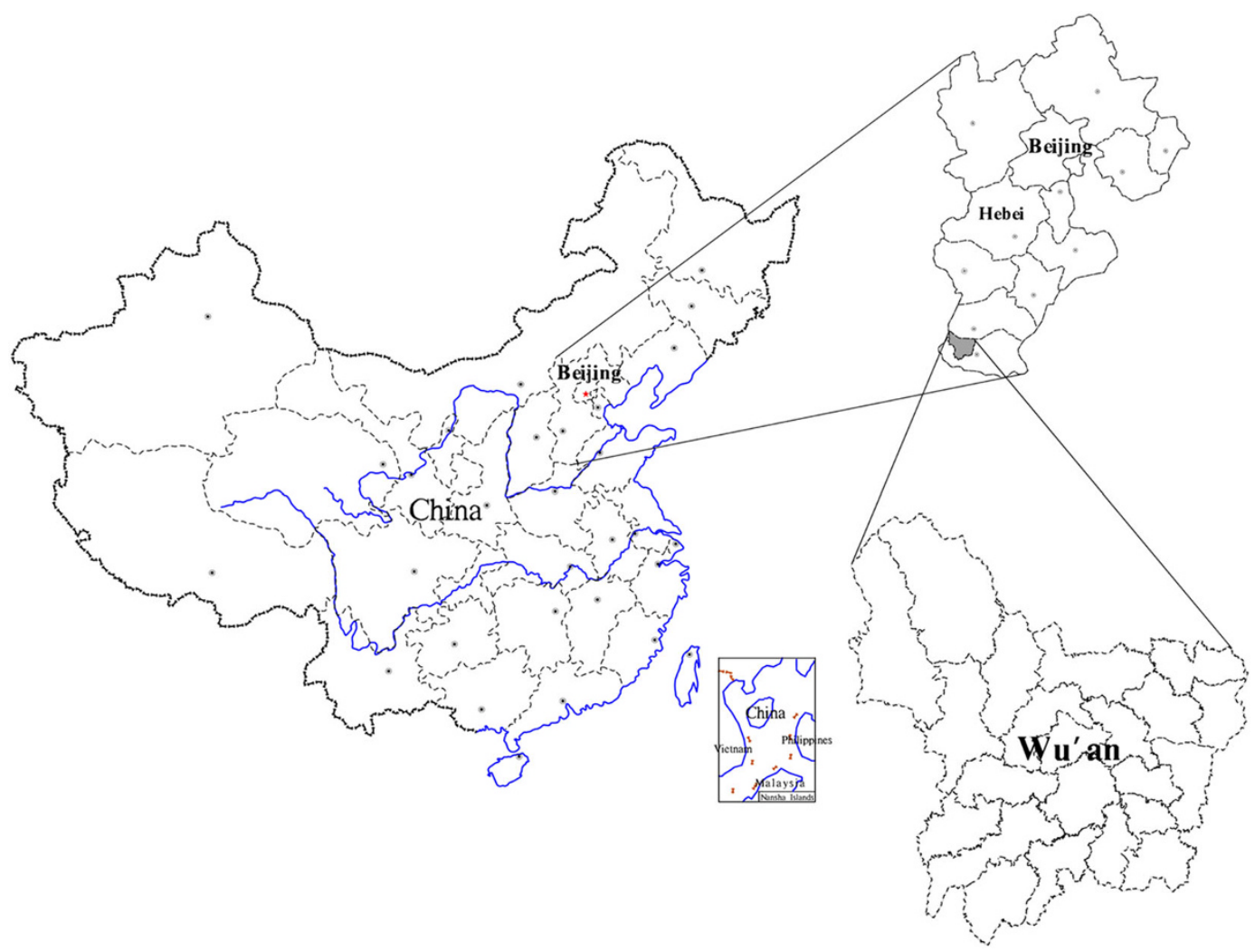

Fig. 1 Location of Wu'an in Hebei Province, China

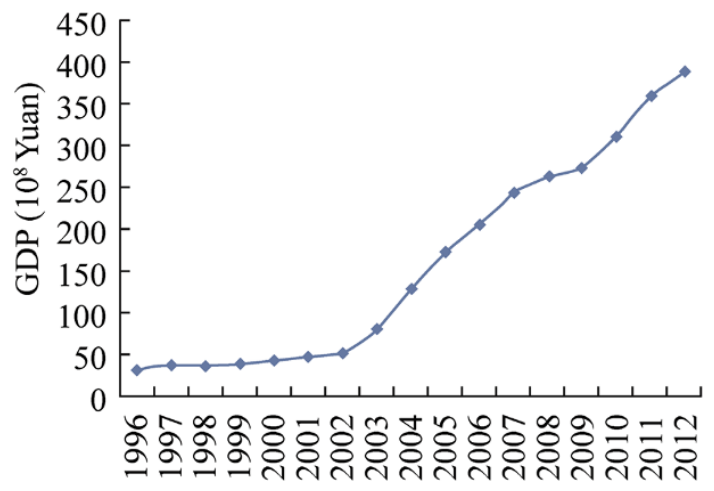

Fig. 2 Industrial GDP growth of Wu'an

grain sizes, especially before and after intensive mining. Mining results in the destruction and fragmentation of original landscapes and the appearance of new landscapes and small plots. The more drastically mining activities proceed, the more frequently landscapes change. Therefore, this paper plans to analyze the effects of grain size on landscape patterns by an example of mineral resource zones in Wu' an of Hebei Province, China. Following it, this paper pursues the following key objectives: (1) the characteristics of landscape indices with different grain sizes before and after intensive mining; (2) the selection of suitable grain sizes for revealing landscape patterns impacted by mining.

\section{Materials and methods}

\subsection{General situation of study area}

Wu'an lies in the hinterland of the Zhongyuan Economic Zone in China, covering a surface area of $1,819 \mathrm{~km}^{2}$, located between $113^{\circ} 45^{\prime}$ and $114^{\circ} 22^{\prime} \mathrm{E}, 36^{\circ} 28^{\prime}$ and $37^{\circ} 01^{\prime} \mathrm{N}$ (Fig. 1). It is high in the west and low in the east, with a small basin called Wu'an Basin in the middle. Wu'an is an important energy supplier in Hebei Province, rich in coal, iron, cobalt, aluminum and others. It also has rich tourism resources including a national geopark and a mine park. In 2006, Wu'an was selected as the "Top Tourist City of China".

\subsection{Data sources and processing}

\subsubsection{Selection of data}

Wu'an is a traditional mining city with a history over several thousand years. But large-scale and intensive mining activities commence after 2002, characterized by industrial GDP growth speed (Fig. 2). Figure 2 shows two significant inflection points around 2002 and 2009. On that, the relevant documents and data were checked for changes. It is believed that the investment intensity of mining activities is enhanced after 2002 and structural intensity 

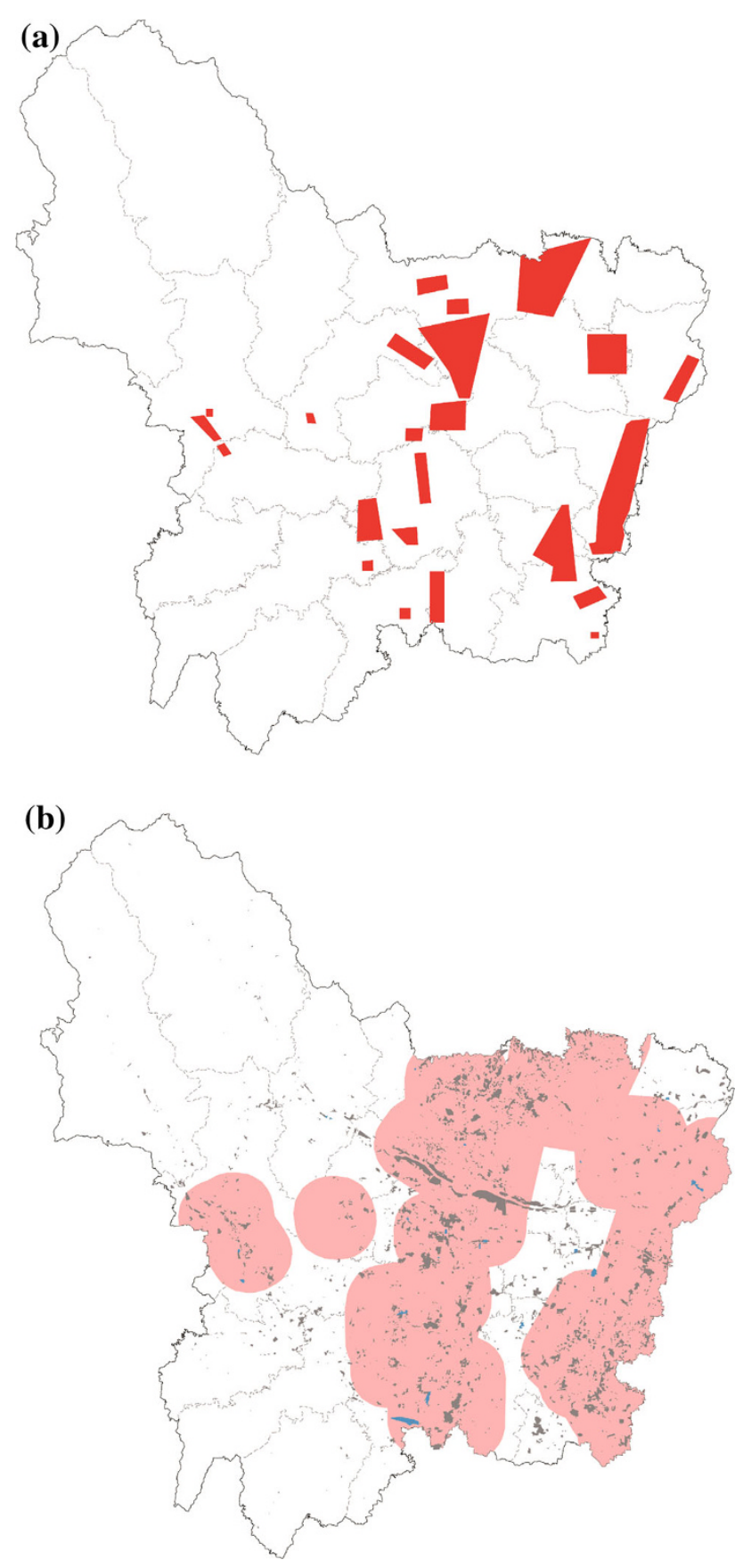

Fig. 3 Distribution of mineral resources (buffer zones) and industrial land. a Distribution of minerals, b Overlying $3 \mathrm{~km}$ buffer zones

after 2009. Considering possible impact of economic buffering and collected data and documents, this paper finally selected land use database in 1996, 2005 and 2012, representing three types of mining intensity, as data sources.

\subsubsection{Definition of mineral resource zones}

The distribution of mineral resources can be got according to General Plan of Mineral Resources in Wu' an (2000-2020).

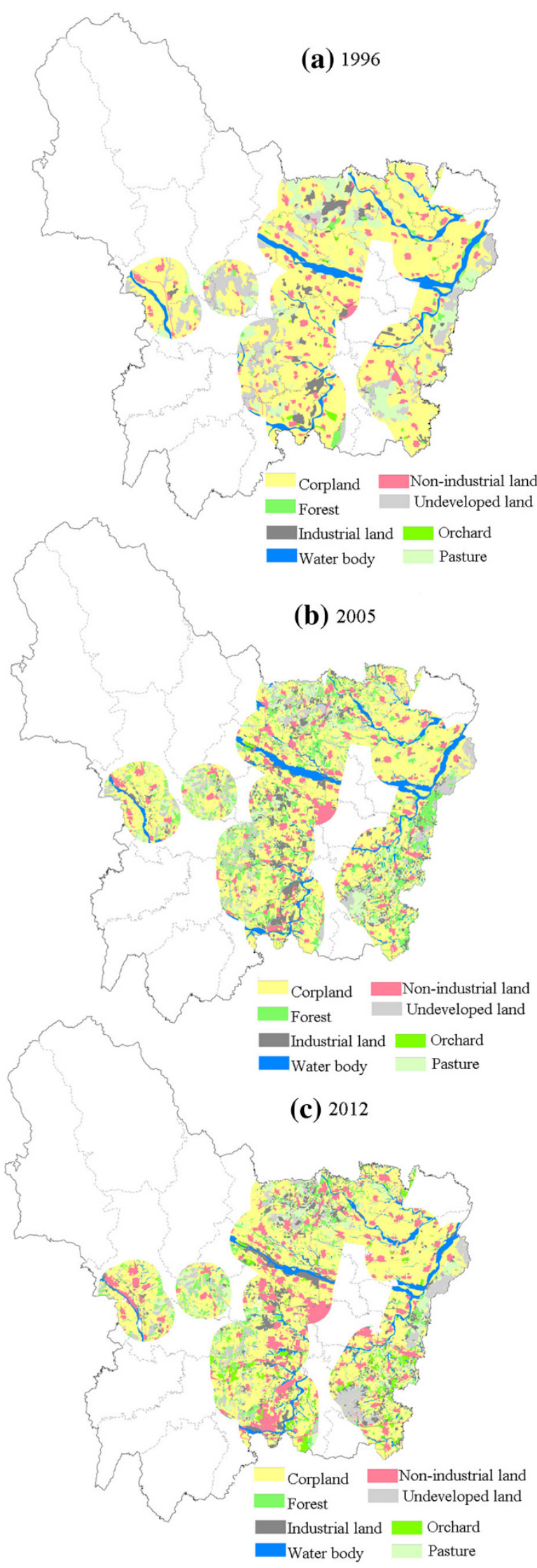


4Fig. 4 Landscape patterns of mineral resource zones in a 1996, b 2005 and c 2012

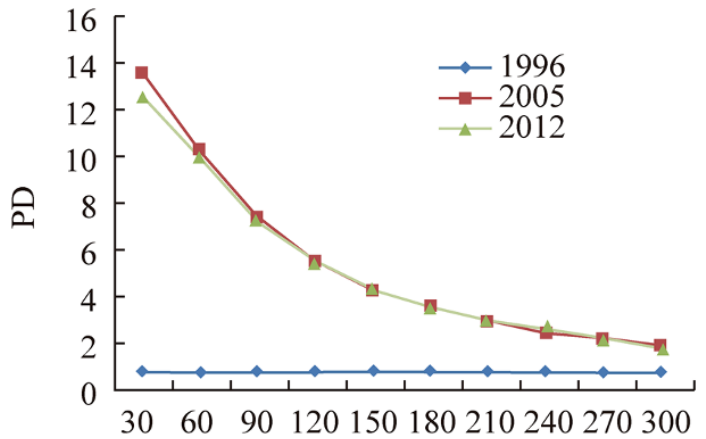

(m)

(a) PD

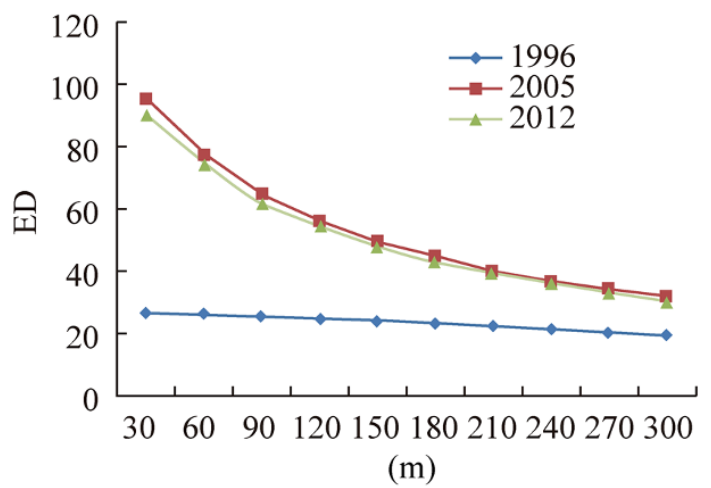

(b) ED

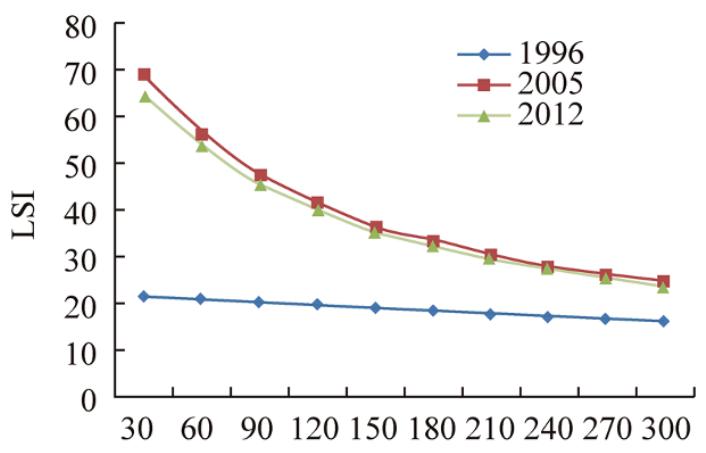

(m)

(c) LSI

Fig. 5 Response of landscape indices for disturbance to grain sizesstable reduction. a PD, b ED and $\mathbf{c}$ LSI

In the previous research about land use changes caused by mining activities, the areas around $3 \mathrm{~km}$ apart from the distribution of mineral resources are where landscape patterns are impacted most. Considering the involvement of possibly impacted land use patterns, the butter zones with $3 \mathrm{~km}$ apart from the distribution of mineral resources are taken as mineral resource zones (Fig. 3). The figure tells us that the $3 \mathrm{~km}$ buffer zones cover most of industrial land so that the
Table 1 Classification of landscape indices and connotations

\begin{tabular}{|c|c|c|}
\hline Aspect & Index & Connotation \\
\hline Disturbance & $\begin{array}{l}\text { PD, ED, LPI, LSI, } \\
\text { AREA_MN, } \\
\text { SHAPE_MN, } \\
\text { PRAC_MN }\end{array}$ & $\begin{array}{l}\text { Reflecting the } \\
\text { fragmentation on } \\
\text { landscape scale and on } \\
\text { patch scale under the } \\
\text { external disturbance }\end{array}$ \\
\hline Continuity & $\begin{array}{l}\text { CONTAG, } \\
\text { COHESION, } \\
\text { DIVISION, SPLIT }\end{array}$ & $\begin{array}{l}\text { Reflecting the aggregation } \\
\text { among the same type of } \\
\text { patches and between one } \\
\text { type and another under } \\
\text { the external disturbance }\end{array}$ \\
\hline Sustainability & PR, SHDI, SHEI & $\begin{array}{l}\text { Reflecting the balance and } \\
\text { possible resilience of } \\
\text { various types of patches } \\
\text { under the external } \\
\text { disturbance }\end{array}$ \\
\hline
\end{tabular}

mapping buffer zones can be as mineral resource zones for a description of landscape patterns.

\subsubsection{Landscape patterns of mineral resource zones}

In this paper, landscape patterns of mineral resource zones were got by overlaying the map of mineral resources distribution with $3 \mathrm{~km}$ buffer and the map of present land use. With the intensify of mining, landscape patterns go towards fragmentation. In the 3 years, farmland still dominated landscapes, accounting for over half of the total area but for more in 1996. The change of built-up land lay in an increasing trend. However, pasture and undeveloped land decreased. From Fig. 4, the matrix of farmland in 1996 was disturbed by other types of landscapes later. On the one hand, farmland was occupied by built-up land; on the other hand, farmland was converted into other ecological land.

\subsubsection{Grain sizes}

As analysis above, landscape patterns may respond to grain sizes. According to relevant provisions of Hebei Province, the safe distance apart from mining areas is designated to $300 \mathrm{~m}$. Therefore, the largest grain size is set at a scale of $300 \mathrm{~m}$ with an interval of $30 \mathrm{~m}$ for determining various grain sizes. As a results of that, 10 grain sizes of 30,60 , $90,120,150,180,210,240,270$ and $300 \mathrm{~m}$ are selected to analyze effects on landscape patterns in mineral resource zones, by means of GIS output function of cell sizes.

\subsubsection{Landscape indices}

This paper selects a series of landscape indices to reveal the effects of grain size on landscape patterns in mineral resource zones, including Patch Density (PD), Edge Density (ED), Largest Patch Index (LPI), Landscape Shape Index 


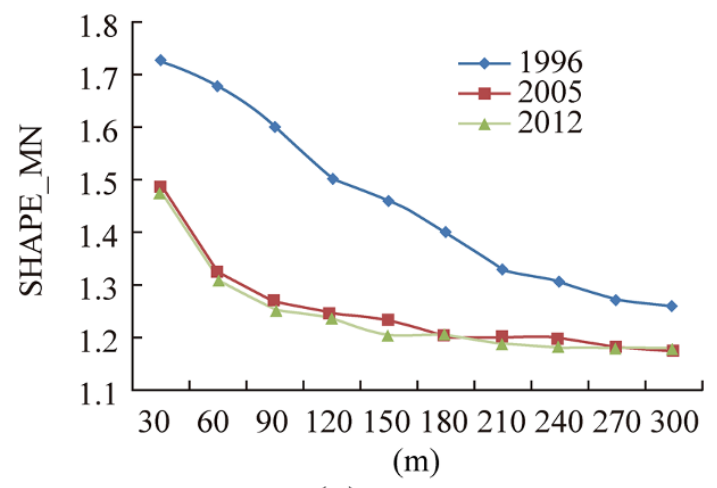

(a) SHAPE_MN

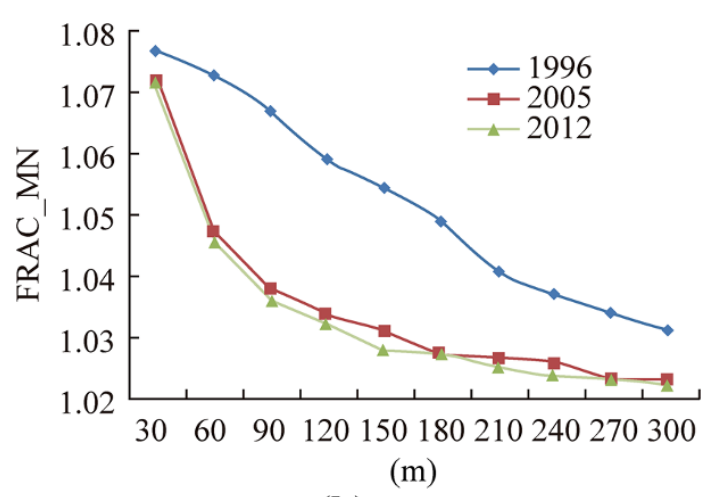

(b) PRAC_MN

Fig. 6 Response of landscape indices for disturbance to grain sizesfluctuant reduction. a SHAPE_MN, b PRAC_MN

(LSI), Mean Patch Area (AREA_MN), Mean Shape Index (SHAPE_MN), Mean Patch Fractal Dimension (PRAC_ MN), Mean Perimeter Area Ratio (PARA_MN), Perimeter Area Fractal Dimension (PAFRAC), Contagion index (CONTAG), Interspersion Juxtaposition Index (IJI), Patch Cohesion Index (COHESION), Landscape Division Index (DIVISION), Splitting Index (SPLIT), Shannon's Diversity Index (SHDI) and Shannon's Evenness Index (SHEI). These landscape indices are classified into three types: disturbance, continuity and sustainability, representing different characteristics of landscape patterns (Table 1).

\section{Results}

The effects of grain size on landscape patterns in mineral resource zones are presented in the three aspects of disturbance, continuity and sustainability. And each aspect is jointly described by a few landscape indices, charted in three curves of 1996, 2005 and 2012.

\subsection{Disturbance}

Figures 5, 6 and 7 show that the changes of landscape indices in 1996 greatly differ from those in 2005 and 2012,

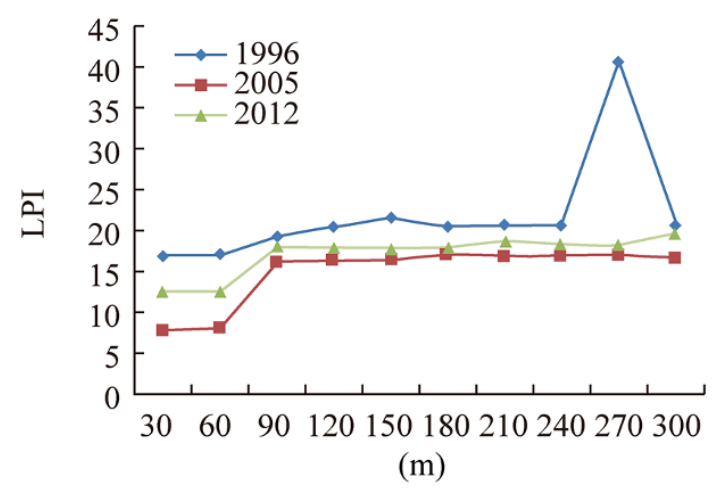

(a) LPI

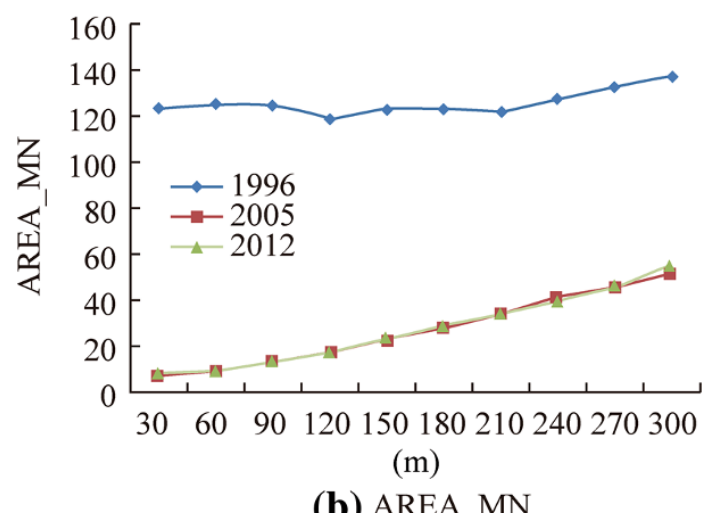

Fig. 7 Response of landscape indices for disturbance to grain sizesfluctuant increase. a LPI, b AREA_MN

Here, it is believed that the intensity of mining has seriously impacted landscape patterns. Before intensive mining, changes of landscape tend to be smooth or slightly fluctuated, having different running tracks in scales of grain sizes compared with those in mining-intensively periods. But there seem to be no significant variations about landscape patterns between 2005 and 2012.

The effects of grain size on landscape indices for disturbance are classified into three types of changing trends.

Type 1 is stable reduction, represented by PD, ED and LSI. For this type of landscape indices, there are no apparent inflection points for effects of grain size. With an increase of grain sizes, the shape and edge of landscape patches tend to be simple, but a sharp decrease appear at the scale of 30-150 m after intensive mining.

Type 2 is fluctuant reduction, represented by SHAPE_MN and PRAC_MN. For SHAPE_MN, the inflection points lie at various scales of various years: 120 and $210 \mathrm{~m}$ in 1996, no points in 2005, 150 and $180 \mathrm{~m}$ in 2012. On that, the first domain of scale is determined at $30-120 \mathrm{~m}$. For PRAC_MN, the inflection points lie at 120 and $210 \mathrm{~m}$ in 1996, no apparent points both in 2005 and 2012. So the first domain of scale is also determined at $30-120 \mathrm{~m}$.

Type 3 is fluctuant increase, represented by LPI and AREA_MN. For LPI, the inflection points lie at various 


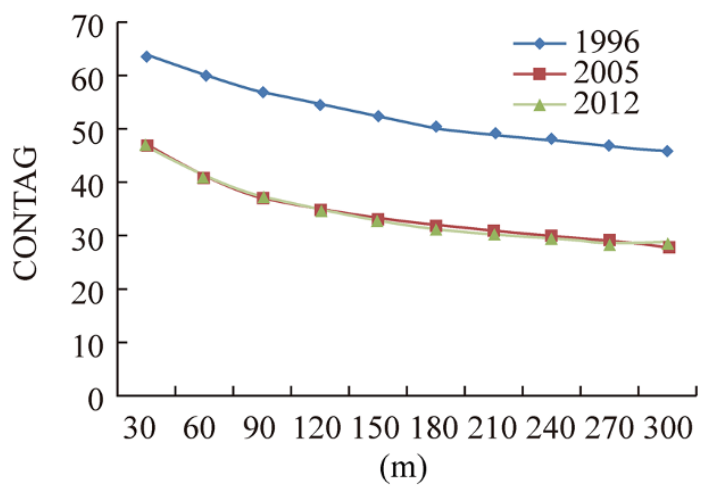

(a) CONTAG

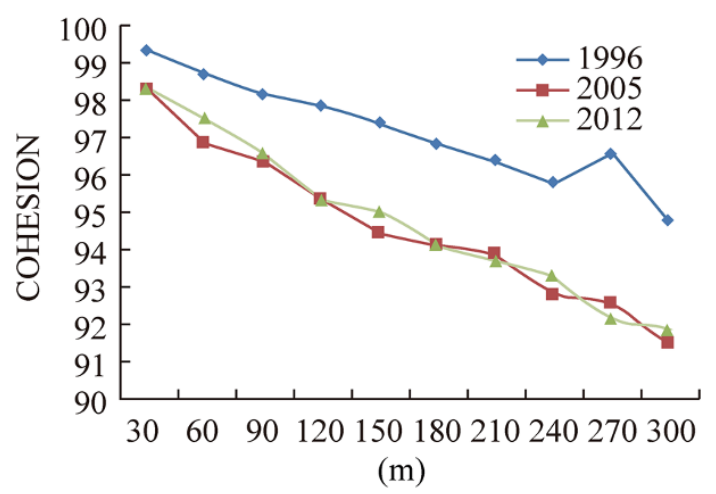

(b) COHESION

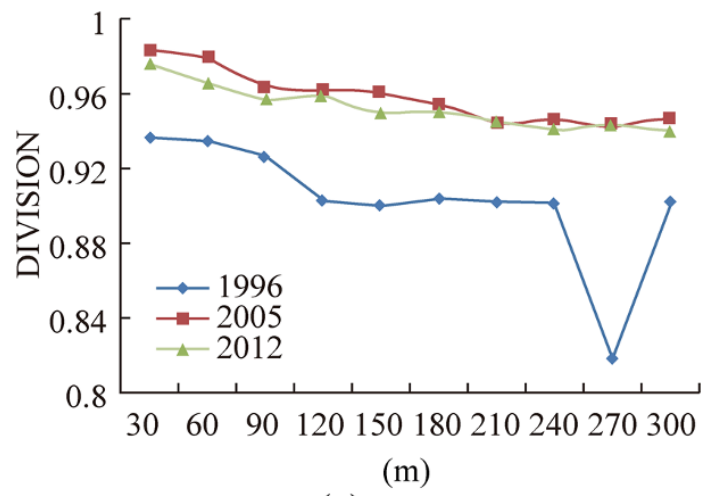

(c) DIVISION

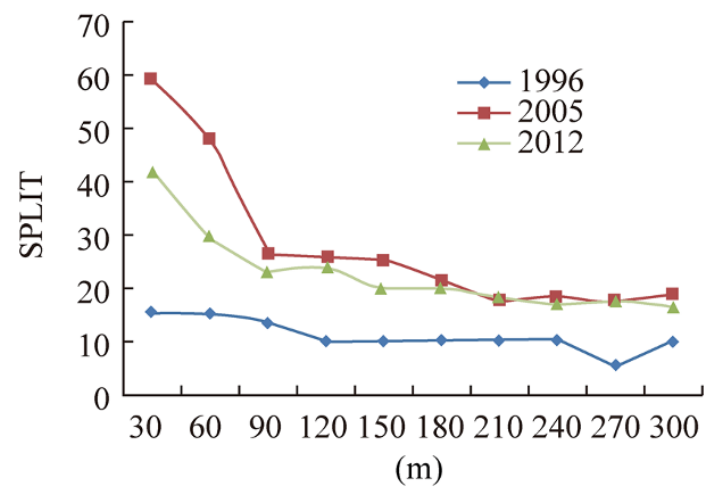

(d) SPLIT

Fig. 8 Response of landscape indices for continuity to grain sizes. a CONTAG, b COHESION, c DIVISION and d SPLIT

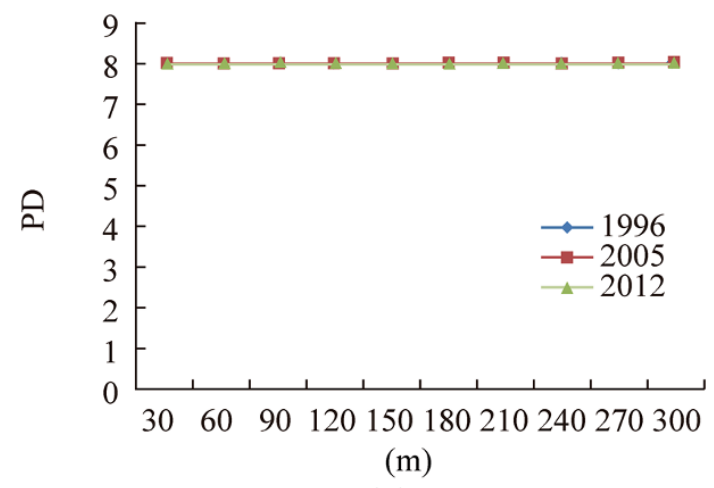

(a) PR

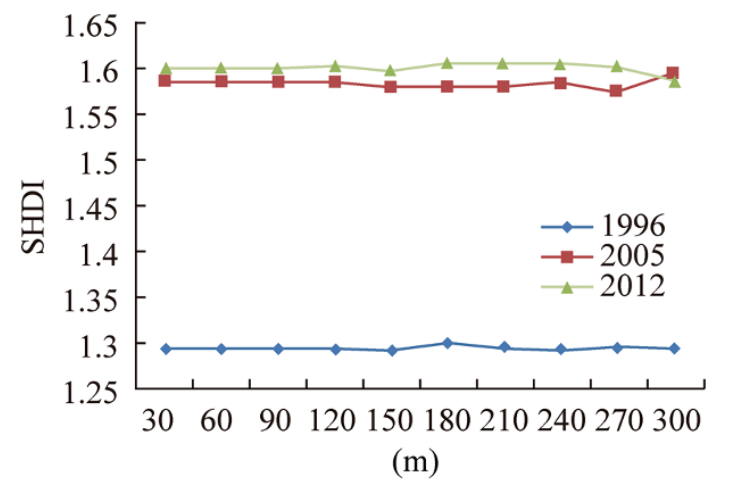

(b) SHDI

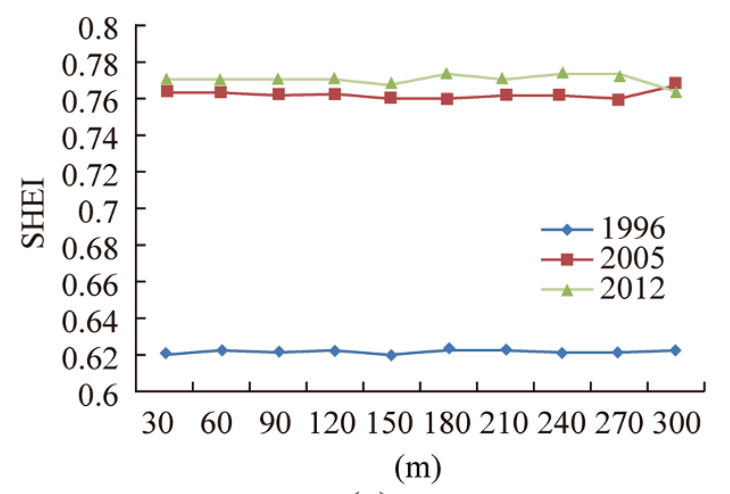

(c) SHEI

Fig. 9 Response of landscape indices for sustainability to grain sizes. a PR , b SHDI and c SHEI

scales of various years: $90,180,210,240$ and $270 \mathrm{~m}$ in 1996, 90, 150, 180, 210 and $240 \mathrm{~m}$ in 2005, 90, 120, 210 and $240 \mathrm{~m}$ in 2012. On that, the first domain of scale is determined at 30-90 m. For AREA_MN, the inflection points lie at 120 and $210 \mathrm{~m}$ in 1996, no points both in 2005 and 2012. So the first domain of scale is determined at 30-120 m.

\subsection{Continuity}

Figure 8 shows that the changes of landscape indices in 1996 moderately differ from those in 2005 and 2012. Here, it is believed that the intensity of mining has moderately impacted 
Table 2 Suitable grain sizes for landscape indices

\begin{tabular}{|c|c|c|c|c|c|}
\hline \multirow[t]{2}{*}{ Aspect } & \multirow[t]{2}{*}{ Index type } & \multirow[t]{2}{*}{ Index } & \multirow{2}{*}{$\begin{array}{l}\text { First domain } \\
\text { of scale (m) }\end{array}$} & \multicolumn{2}{|l|}{ Suitable grain size } \\
\hline & & & & $\begin{array}{l}\text { Before intensive } \\
\text { mining }(m)\end{array}$ & $\begin{array}{l}\text { After intensive } \\
\text { mining }(\mathrm{m})\end{array}$ \\
\hline \multirow[t]{7}{*}{ Disturbance } & \multirow[t]{3}{*}{ Stable reduction } & PD & No & No & No \\
\hline & & ED & No & No & No \\
\hline & & LSI & No & No & No \\
\hline & \multirow[t]{2}{*}{ Fluctuant reduction } & SHAPE_MN & $30-120$ & $30-60$ & $90-120$ \\
\hline & & PRAC_MN & $30-120$ & $30-60$ & $90-120$ \\
\hline & \multirow[t]{2}{*}{ Fluctuant increase } & LPI & $30-90$ & $30-60$ & $30-60$ \\
\hline & & AREA_MN & $30-120$ & $30-60$ & $30-60$ \\
\hline \multirow[t]{4}{*}{ Continuity } & Stable reduction & CONTAG & No & No & No \\
\hline & \multirow[t]{3}{*}{ Fluctuant reduction } & COHESION & $30-90$ & $60-90$ & $60-90$ \\
\hline & & DIVISION & $30-90$ & $30-60$ & $30-60$ \\
\hline & & SPLIT & $30-90$ & $30-60$ & $60-90$ \\
\hline \multirow[t]{3}{*}{ Sustainability } & Horizontal constant & PR & $30-300$ & $30-300$ & $30-300$ \\
\hline & \multirow[t]{2}{*}{ Horizontal fluctuation } & SHDI & $30-90$ & $30-90$ & $30-90$ \\
\hline & & SHEI & $30-90$ & $30-90$ & $30-90$ \\
\hline
\end{tabular}

the continuity of landscapes. It is still that there seem to be no significant variations about landscape patterns between 2005 and 2012. The effects of grain size on landscape indices for continuity include two types of changing trends.

Type 1 is stable reduction, only represented by CONTAG. There are no inflection points in any year of 1996 , 2005 and 2012. Type 2 is fluctuant reduction, represented by COHESION, DIVISION and SPLIT. For COHESION, the inflection points lie at 120,180, 210, 240 and $270 \mathrm{~m}$ in 1996, 90, 210, 240 and $270 \mathrm{~m}$ in 2005, 120, 150, 180, 240 and $270 \mathrm{~m}$ in 2012. So the first domain of scale is also determined at $30-90 \mathrm{~m}$. For DIVISION, the inflection points lie at 120, 180, 210, 240 and $270 \mathrm{~m}$ in 1996, 90, 120, $180,210,240$ and $270 \mathrm{~m}$ in $2005,120,150,180,210$ and $270 \mathrm{~m}$ in 2012 . Thus, the domain of scale is determined at $30-90 \mathrm{~m}$. And for SPLIT, the inflection points are 120, 180, 210, 240 and $270 \mathrm{~m}$ in 1996, 90, 120, 210, 240 and $270 \mathrm{~m}$ in 2005, 120, 150, 180, 210 and $270 \mathrm{~m}$, determining $30-90 \mathrm{~m}$ as the first domain of scale.

\subsection{Sustainability}

The curves in Fig. 9 seems to go along a horizontal change, classified into two types: horizontal constant and horizontal fluctuation. However, the changing fluctuation of landscape indices in 1996 is similar to those in 2005 and 2012. Here, it is believed that the intensity of mining has a slight influence on landscape patterns. The enhancing intensity of mining does not yield a significant function to spatial allocation of landscapes. As a result of that, the effects of grain size in landscape indices for sustainability are not apparent before and after intensive mining. But after a comparison of the curves, $30-90 \mathrm{~m}$ is still the first domain of scale.

\subsection{Comparisons of grain sizes}

Landscape indices indicate various characteristics information of scales with a change of grain sizes. In order to guarantee the quality of calculation, reflect the characteristic information of scale and control calculating workloads, medium to large grains in the first domain of scale are suitably selected to measure landscape patterns (Zhao et al. 2003). Besides, the sector with a smooth change is better for consideration in selecting suitable grain sizes. Table 2 shows that the first domain of scale covers $30-120 \mathrm{~m}$, but the common domain is $30-60 \mathrm{~m}$ before intensive mining. After intensive mining, landscape patterns are impacted drastically, and the suitable grain sizes are different for landscape indices. But $60-90 \mathrm{~m}$ is relatively good as suitable grain size. For the three aspects of landscape indices, the suitable grain size is also different. Based on comprehensive analysis, the suitable grain sizes for reflecting disturbance, continuity and sustainability before intensive mining are 30-60, 30-60 and 30-90 m, respectively, however, the sizes are changed to 60-90, 60-90 and 30-90 m, respectively, after intensive mining.

\section{Conclusions and discussion}

\subsection{Main achievements}

This study is an initial trial to reflect the response of landscape indices to grain sizes, impacted by mining activities. It is believed that mining activities have a significant influence on landscape patterns, but there is no 
apparent difference between investment intensity and structural intensity. Mining activities force landscape patterns to fragmentation. This paper selected a series of grain sizes to seek their relationships with landscape indices in mineral resource zones. It is proven that landscape indices after intensive mining respond to grain sizes more greatly than before. The best first domain of scale covers 30-90 m, with a suitable grain size of $30-60 \mathrm{~m}$ before intensive mining and a suitable grain size of $60-90 \mathrm{~m}$ after intensive mining, which indicates that mining activities have forced surrounding landscapes to a more drastic change. In terms of the three aspects of disturbance, continuity and sustainability, the intensity of mining activities alters the shape, distribution and proximity relation of patches most, but the number and richness of landscape types cannot be primarily changed.

\subsection{Limitations and uncertainty}

The conclusions in this paper are based on land use database of 1996, 2005 and 2012. It is impossible to judge and compare the accuracy of these vector maps, which impacts the analytical processes and results. If remote sensing images are used, the results may be better, at least towards a synchronous error. Additionally, this study only selects ten grain sizes with an interval of $30 \mathrm{~m}$, it needs doing more practices and attempts to verify the optimal selection. But the paper can make some reliable conclusions to some extent.

Acknowledgments This article is supported by National Natural Science Foundation of China (Grant No. 41101531), Doctoral Fund of
Ministry of Education of China (New Teacher Fund) (Grant No. 20110022120010) and Beijing Higher Education Young Elite Teacher Project (No. YETP0639). Also, authors gratefully acknowledge the colleagues and friends in Land Resources Bureau of Wotan for offering the basic data and the relevant information.

Open Access This article is distributed under the terms of the Creative Commons Attribution License which permits any use, distribution, and reproduction in any medium, provided the original author(s) and the source are credited.

\section{References}

Li JF (2004) The system study of the strategic evaluation of mineral resources. Doctoral dissertation, China University of Geosciences, Wuhan

McIntyre S, Lavorel S (2007) A conceptual model of land use effects on the structure and function of herbaceous vegetation. Agric Ecosyst Environ 119:11-21

Qi Y, Wu JG (1996) Effects of changing spatial resolution on the results of landscape pattern analysis using spatial autocorrelation indices. Landsc Ecol 11(1):39-49

Turner MG, O’ Neill RV, Gardner RH, Milne BT (1989) Effects of changing spatial scale on the analysis of landscape pattern. Landsc Ecol 3(3/4):153-162

Vitousek PM, Mooney HA, Lubchenko J, Melillo JM (1997) Human domination of Earth's ecosystems. Science 277:494-499

Yan J, Yang FH, Li FP (1992) A review of land reclamation of metallurgical mines. J Hebei Inst Technol 21:41-47

Zhang JJ, Fu MC, Zeng H, Liu SA (2007) Coordination and control of ecological environment security in mining area: a case study of Wu'an, a mining city in China. In: Wang YJ, Li SC, Huang P, Yang YH, Sun XY (eds) Progress in environment science and technology. Science Press, Beijing, pp 422-426

Zhao WW, Fu BJ, Chen LD (2003) The effects of grain change on landscape indices. Quat Sci 23(3):326-333 